\title{
LOCKE ON IDEAS OF SUBSTANCE AND THE VEIL OF PERCEPTION
}

BY

\section{GIDEON YAFFE}

\begin{abstract}
John Yolton has argued that Locke held a direct realist position according to which sensory ideas are not perceived intermediaries, as on the representational realist position, but acts that take material substances as objects. This paper argues that were Locke to accept the position Yolton attributes to him he could not at once account for appearance-reality discrepancies and maintain one of his most important anti-nativist arguments. The paper goes on to offer an interpretation of Locke's distinction between ideas of substances and modes, a distinction that helps Locke to explain appearance-reality discrepancies, although not in a large enough range of cases to strengthen Yolton's interpretation.
\end{abstract}

Locke's account of the perception of physical objects was received by many in the eighteenth century as a version of representational realism - the view that an object is perceived by virtue of the mind's awareness, of some kind or another, of a mental representation of the object. ${ }^{1}$ Perception of objects, under this interpretation of Locke, proceeds by way of the perception of ideas. Consider, for instance, Thomas Reid's description of Locke's position:

[U]pon Mr. Locke's principles ... we cannot think of Alexander, or of the planet Jupiter, unless we have in our minds an idea, that is, an image or picture of those objects. The idea of Alexander is an image, or picture, or representation of that hero in my mind; and this idea is the immediate object of my thought when I think of Alexander. That this was Locke's opinion ... there can be no doubt (Reid, 2002, p. 133).

As Reid understood Locke, there are three mental items involved in perception, in addition to the physical object perceived: the mind itself, a mental object or representation - that is, an "idea" - and an act of awareness of that idea. Reid criticized representationalist conceptions of perception of the sort

Pacific Philosophical Quarterly 85 (2004) 255-272

(C) 2004 University of Southern California and Blackwell Publishing Ltd. Published by

Blackwell Publishing Ltd, 9600 Garsington Road, Oxford OX4 2DQ, UK and

350 Main Street, Malden, MA 02148, USA. 
that he took Locke to offer on a number of well-known grounds. Reid argues, contra Locke as he reads him, for a direct realist position under which the mind, in perception, contributes only an act and not, also, some mental object. This act is an awareness of an external object, and not an awareness of a mental representation, as on the position that Reid attributes to Locke.

But was Reid interpreting Locke fairly? John Yolton has argued that Locke himself considered ideas to be mental acts and, therefore, the relation between the mental act of awareness of ideas, on the one hand, and ideas themselves, on the other, is one of identity. If this is so, then there is no tertium quid in Locke's theory of ideas, as Reid suggests. ${ }^{2}$ Yolton has drawn on a large number of passages from Locke's corpus to support this point. These passages all seem to avow an explicit equation between "ideas" and "perceptions", or mental acts. ${ }^{3}$ However, any theory of perception must leave room for - and should, ideally, explain - the possibility of discrepancy between appearance and reality. It will be argued here that Locke's views on other subjects preclude him from accepting any of the possible explanations of appearance-reality divergence to which a direct realist would need to appeal in defense of the view. Therefore, although there are admittedly places where Locke sounds like he advocates the view Yolton takes him to hold, it is not his settled view, or a view that he would be ready to accept with all its implications.

When we ask how things appear to a particular agent having a perceptual experience - an experience caused by the agent's senses - the correct answer identifies what is often called "the perceptual content" of the perceptual experience the agent is having. Answers to the question of how things appear can be right or wrong; if there appears to be an oasis on the horizon, then there doesn't appear to be dry desert there. Any satisfactory theory of perception will tell us what features of the world and the mind determine what the perceptual content of a particular person's perceptual experience is. Further, in telling us this, a theory of perception will provide (or attempt to provide) an explanation for the fact that sometimes appearance and reality diverge. Such divergences occur when there fails to be the appropriate line-up between the way things are and the facts about the mind and the world by virtue of which they appear a certain way. On the view Yolton attributes to Locke, what features of what part of the world determine the contents of perceptual states? This question is easy to answer when asked about the view that Reid attributes to Locke. Under that view, the ball appears red because of features of the idea in the mind of the perceiver; it not clear that the idea need be red for the ball to appear red, but something about the idea accounts for the content of the appearance. The discrepancy between the way the world is and the way it appears comes from a discrepancy between the content-fixing feature of the idea and the feature of the world with which it is correlated. On the representational realist view, then, much (and possibly all) perceptual content is determined by the features of ideas. ${ }^{4}$ 
The view Yolton attributes to Locke might take perceptual content to be fixed by a diversity of things. At least in some cases, the content of a perceptual state might be fixed by the intrinsic, non-relational features of the object at which the mental act is directed: what makes this tactile experience one of roughness might be just that the object I'm touching is rough. But perceptual content could not be fixed in this way in cases in which the perceived object is actually intrinsically different from the way it appears. The problem is that the very same things that make it the case that the object is as it is - it's intrinsic features - also play the role of determining how the object appears; without some explanation for why these features play the former role "correctly" and the latter "incorrectly", it is hard to see how there could ever be discrepancy between appearance and reality.

However, there are two other sources of perceptual content to which Yolton's Locke could appeal. First, content could be determined adverbially, à la Ducasse. Perhaps, that is, part of what makes an object appear as it does is the particular way in which one perceives the object. Acts, after all, can have properties - one can wink conspiratorially, for instance; perhaps the properties of the mental act of awareness of objects contributes to the content of the perceptual experience one has when aware of them. Or, second, Yolton's Locke might suggest that perceptual content is determined in part by the features of the object of which one is aware that that object posesses solely because of its relation to the mind. That is, the coin in my palm, for instance, has the property of appearing-ellipticalfrom-such-and-such-a-location. This is not an intrinsic feature of the coin, but, instead, a relational feature of the coin that it possesses in part by virtue of features of the mind. ${ }^{5}$ By appealing to either of these two sources of perceptual content, Yolton's Locke can account for discrepancies between appearance and reality. Since that which fixes the content of the perceptual state - the features of the act, in the first case, or the relational features of the object, in the second - is different from that which determines the features of the object, it seems possible that the two could fail to line-up as they do when things are as they appear.

But could Locke accept either of these two sources of perceptual content and their accompanying explanations of appearance-reality divergence? Against Yolton's reading of Locke, it will be argued that neither source of perceptual content is consistent with Locke's settled philosophical commitments on other issues. Although there is some evidence to suggest that Locke does take discrepancies between appearance and the intrinsic features of reality to be accounted for through appeal to the perception of relational qualities, such a view ultimately depends on some perceptual content being determined adverbially. Further, Locke cannot accept the adverbial view. He cannot hold that there is anything about the mental act of awareness of ideas that contributes to the content of perception without giving up one of his most interesting arguments against nativism. If the 
argument for these claims succeeds, it follows, at the least, that Locke does not accept the full implications of the view that Yolton attributes to him. Thus, either Yolton's equation between ideas and the mental acts misleadingly referred to as "perceptions of ideas" is not, in fact, advocated by Locke, or else in cases of divergence between appearance and intrinsic reality Locke takes the content of a perceptual state to be fixed by something other than either the manner in which the mental act is performed, or the relational features of the perceived object. But what else could do the needed job? In the absence of an answer to that question, Locke ought to be attributed with just the view that Reid attributes to him: perception of objects proceeds by virtue of the perception of ideas. However, as will emerge, Locke does think there is a way in which the content of an inaccurate perceptual state can be fixed by something other than the features of the immediate object of the mental act, or by the way in which that act is performed. But it will be argued that, while interesting in itself, the fact that Locke acknowledges this further source of perceptual content still does not provide Yolton with the position that he wants.

\section{The perception of relational qualities}

Can Locke hold that when appearance and reality seem to diverge what is really happening is that a relational property of an object is being perceived that does not match any non-relational, intrinsic, feature of the object? If so, then Yolton's Locke could account for appearance-reality discrepancy this way. To take this line would be to insist that there is a sense in which appearance and reality never do diverge. The sense in which two trees of the same size, seen from different distances, appear to differ in size is just this: the two trees actually have the quality of appearing to be different in size when looked at from such-and-such distances. There is evidence to suggest that Locke does hold this position. This section argues, however, that the position itself is parasitic on a view under which some perceptual content is fixed adverbially, that is, by means of the manner of awareness in which the perceiver engages.

Locke makes a point, in a number of places, of saying that powers are relational features of objects (cf. Essay II.xxi.3). He also associates the secondary qualities with powers to produce various sensory ideas (cf. Essay II.viii.10). And, when diagnosing the mistake that people make in the attribution of sensible qualities to objects, he writes,

But though [ . . . secondary qualities ... ] are Powers barely, and nothing but Powers, relating to several other Bodies, and resulting from the different Modifications of the Original Qualities; yet they are generally otherwise thought of . . . The Powers to produce several Ideas in us by our Senses, are looked upon as real Qualities, in the things thus affecting us (Essay II.viii.24). 
Notice the talk of "relation" in this passage. Secondary qualities, he seems to be saying, are nothing but relational properties that "result" from the intrinsic properties of the relata. In the case of sensible qualities, such as colors, the relata are the object and the perceiver. What Locke seems to suggest here is that the discrepancy between the way things really are and the way they appear with respect to color is really a mistake in the way in which colors are "thought of", or attributed, and not a mistake in the way they are seen. We think of the color that we are seeing as an intrinsic quality of the object perceived rather than thinking of it as what it actually is, a relational quality of the object: being such as to cause in me certain ideas in normal conditions. This is to offer just the sort of account of the discrepancy between appearance and reality that Yolton's view requires. What are really being perceived in such cases are relational properties that are mistakenly taken to be intrinsic.

What is it to "take" a perceived relational property to be intrinsic? Perhaps it is to assign content to a perceptual experience different from the actual content of that experience. The perceiver might, for instance, report herself to be seeing an intrinsic property of the apple when she sees it as red when, in fact, the immediate object of her perception is a relational property. But then where does the content assigned, or "reported", come from? We might think of what's going on like this: There are intrinsic features of the object - a particular surface texture, for instance - and there are intrinsic features of the mind - a sensation or a state having what-it's-like qualities. The perceiver is really perceiving a relation between the object and the mind that depends, at least in part, on the intrinsic features of each. But the perceiver then assigns the content of one mental state (the sensation) to another (the perception of the relational feature). Under this analysis, there remains a contentful mental state the content of which needs to be accounted for. That is, there is an actual contentful mental state - a sensation - the content of which is being confused with another, the perception of the relational feature. But then what fixes the content of the sensation?

There appear to be three possible answers to this question: (1) An intrinsic property of the mind, (2) The question needs no answer, since the sensation has no content, or (3) The content of the sensation is fixed adverbially; that is, through the manner in which the relational feature of the object is being perceived. As I am about to argue, the first two of these options are untenable, and so Yolton's Locke is required to accept that some mental content is fixed adverbially.

(1) On this view, the sensation is a perception of an intrinsic feature of the mind and it is, therefore, that feature that fixes the content of the sensation. It would seem, on this view, that the perceived feature of the mind must be possessed by the mind in virtue of the fact that the sensation is taking place. Hence there are two aspects of the sensation: there is the 
manifestation of some special feature, and there is the perception of this feature. The perceived feature is then mistakenly judged to belong to the object causing the sensation rather than to belong to the mind itself. The mind is, on this view, spread on the world. It appears, then, that in so far as it is a bearer of a perceived feature being ascribed to the object, the sensation is playing the very same role that ideas play under an indirect realism of the sort that Reid ascribed to Locke. To see this consider cases of veridical perception (say the perception of the sphericality of a sphere) and compare them to qualitatively identical cases of illusion (say the perception of the sphericality of a carefully painted flat, round disk). It is hard to see why the judgment (i.e. "That's a sphere.") should have a different etiology in the latter cases than it does in the former. But we are told that in the latter cases, the judgment arises from an ascription of a quality of the sensation to the object. If that's how the judgment arises in the former cases, however, then Yolton's Locke is committed to the view that sensations serve as perceptual intermediaries allowing for the perception of the qualities of objects that cause them. This is to give up the game, since the view to which we've been reduced is no different from the view that Reid attributes to Locke.

(2) We could claim that the sensation actually has no content, and so, of course, nothing determines its content. Notice that on this view the person to whom reality appears otherwise than it is is making two mistakes: first, she is taking her sensation to have content when it actually has none, and then she is assigning that content - which is actually nothing at all - to the experience of the object, the actual content of which is the object's relational feature. If this view is coherent at all, it encounters problems with regress: what is it to "take" one's sensation to have content when it does not? Either that "taking" is a contentful mental state, in which case we are back where we began - what fixes its content? - or else it is contentless. But if it is contentless, how can its content be assigned to another mental state?

(3) Yolton's Locke should answer that the content of the sensation is fixed adverbially. That is, the object has a relational feature - being such as to appear a certain way - and the perceiver is perceiving that feature in a particular way; red-ly, say. To speak of the sensation, on this view, is simply to speak of the mental act in which the perceiver engages in isolation from that act's immediate object (namely the object's relational quality). Even subtracting its object, however, this mental act has content by virtue of the manner in which it is being performed. If this third answer is, as it appears, the only viable answer, then the Yolton interpretation requires appeal to the adverbial view of the source of mental content, even if perceptual content is thought to be fixed, in part, by the relational features of the perceived object. It is to the adverbial approach that I now turn. 


\section{Ways of perceiving}

So, consider the suggestion that Locke takes perceptual content to be fixed adverbially. To see a red apple is to see an apple red-ly. What I'll argue in this section is that such a position is inconsistent with one of Locke's more interesting arguments in his attack on innate ideas in Book I of the Essay.

Locke's oft-maligned argument against innate ideas is far more interesting than it is usually given credit for being. Perhaps the reason that it is so often maligned is that the real insight of the discussion is not to be found so much in Locke's anti-nativist conclusion as it is to be found in his way of getting there: his remarkably nuanced and systematic examination of the various senses in which the content of a thought can be said to be "in a person's mind" when it is so obscured from her view that she would not assent to propositions involving it. Those with nativist sympathies - Leibniz prominent among them (cf. Leibniz, 1981, pp. 90-91) always insist that there is a sense in which content can be in the mind that Locke fails to notice, and, further, that that sense is the most important one for establishing the nativist position. If Locke thought that perceptual content could derive from the manner of perception - the adverbial view that could supplement Yolton's interpretation - then, as I'll argue, Locke would have to allow a sense in which content could be in the mind that would undermine the force of one of his best anti-nativist arguments. I will not be arguing that an adverbialist about mental content must be a nativist - a claim which is probably false, in any event. Rather, I'm going to argue that an adverbialist about mental content cannot accept one of Locke's more interesting anti-nativist arguments; an adverbialist might reject nativism on other grounds - on grounds, even, that Locke himself offers against nativism in other contexts. Even if I'm right, this is no vindication of Locke's anti-nativist argument, since perhaps he should have allowed that content could be fixed through the manner of perception. However, it is very strong evidence that Locke would eschew a way of understanding what it is for content to be in the mind that Yolton's interpretation would have him accept.

After having dispensed with explicit, occurrent, universal knowledge of a proposition as a test for innateness, Locke goes on to consider a subtler view of the sense in which a proposition can be in the mind prior to experience. According to this alternative, a proposition is in a person's mind if she would grasp it were she to exercise her capacity for reason. Locke responds,

... By this Means there will be no difference between the Maxims of the Mathematicians, and Theorems they deduce from them: All must be equally allow'd innate, they being all Discoveries made by the use of Reason, and Truths that a rational Creature may certainly come to know, if he apply his Thoughts rightly that Way (Essay I.ii.8). 
The loss of a distinction in innateness between the axioms and the theorems of mathematics might not, itself, be considered much of a loss. Why shouldn't the theorems be innate? However, Locke goes on to explain why it is a loss: it implies that no propositions are genuinely axiomatic. He writes:

[I]t must be confessed, that in their [logical axioms] Discovery, there is no Use made of reasoning at all. And I think those who give this Answer, will not be forward to affirm, That the Knowledge of this Maxim, That it is impossible for the same thing to be, and not to be, is a deduction of our Reason. For this would be to destroy that Bounty of Nature, they seem so fond of, whilst they make the Knowledge of those Principles to depend on the labour of our Thoughts. For all Reasoning is search, and casting about, and requires Pains and Application. And how can it with any tolerable Sence be suppos'd, that what was imprinted by Nature, as the Foundation and Guide of our Reason, should need the Use of Reason to discover it? (Essay I.ii.10).

It is tempting to read this passage as a statement of the blustering theological point that a nativist of the sort under discussion is committed to a characterization of the creator as one who gives us knowledge while, for no particular reason, making it difficult for us to grasp. This point does contribute to the rhetorical force of the passage, but Locke has a more important point in mind, a point deriving from his view of reason as the discovery of, and perception of agreement between, intermediate ideas and those involved in a demonstrable or probable proposition. $\mathrm{He}$ describes this view in Book IV of the Essay:

[Reason] is necessary, and assisting to all our other intellectual Faculties, and indeed contains two of them, viz. Sagacity and Illation. By the one, it finds out, and by the other, it so orders the intermediate Ideas, as to discover what connexion there is in each link of the Chain, whereby the Extremes are held together; and thereby, as it were, to draw into view the Truth sought for, which is that we call Illation or Inference, and consists in nothing but the Perception of the connexion there is between the Ideas, in each step of the deduction, whereby the Mind comes to see, either the certain Agreement or Disagreement of any two Ideas, as in Demonstration, in which it arrives at Knowledge; or their probable connexion, on which it gives or with-holds its Assent, as in Opinion ... [T]he Faculty which finds out the Means, and rightly applies them to discover Certainty in the one, and Probability in the other, is that which we call Reason (Essay IV.xvii.2).

The exercise of reason, then, is a two step process. First we think up intermediate ideas - ideas that will serve to connect, say, the idea of the subject of a proposition and the idea of the predicate; then we perceive the agreement between those intermediate ideas and the ideas they mediate between. ${ }^{6}$ The intermediate ideas provide "the reason for" the proposition grasped through reason. Armed with this account of reason we can ask what it means to say that we grasp an axiom through reason. The answer appears to be that we think up ideas that mediate between the ideas involved in the axiom and perceive the needed agreements. What 
follows is that grasping axioms through reason means understanding reasons for those axioms. But if there are reasons for axioms, their axiomatic status is undermined. An axiom is an axiom because it is true even though there are no reasons in favor of its truth.

There is a nativist response to this argument that would be on the tip of the tongue of anyone who holds that mental content can be fixed adverbially. Perhaps to say that the grasping of a mathematical theorem is an exercise of reason is just to say that it is an act of perceiving - grasping in a particular, distinctive way that brings in the content of the axioms. That is, what makes the perception of the ideas involved in a mathematical theorem a perception of reason is that the act of perception has the form of reason - it involves a manner of perceiving that accounts for the inclusion of the axiomatic propositions in the content of the perception. To perceive a proof, we might say, is to perceive axiomatic-ly. The idea would be that a nativist can account for a distinction between axioms and theorems while still holding that what makes mental content innate is its accessibility through reason alone. To exercise one's reason, on this view, would be to engage in a kind of mental activity that, by its very nature, includes the content of the axioms. The axioms are in the mind through the exercise of reason even though we never could provide reasons for them. The grasping of them, we might say, is the condition of the possibility of the activity of giving reasons for any proposition at all. This is, of course, a very Kantian idea but it is the sort of idea that would be obvious to anyone who held that mental content can be fixed adverbially. Why didn't Locke see it? Answer: Because he doesn't think that mental content can be fixed adverbially.

Let me summarize the argument just offered. Locke considers the following criterion for innateness:

Rational Accessibility Criterion of Innateness: An idea is innate if and only if it can be had solely through the exercise of reason.

He then claims that this criterion of innateness implies the following:

Equality of Axioms and Theorems: The axioms and the theorems of logic and mathematics do not differ in their degree of innateness.

He then invokes the following view of reason which is expressed at large in book IV of the Essay:

Reason as Sagacity and Illation: Reasoning is the process of discovering intermediate ideas and perceiving their agreement with those involved in a proposition.

He then claims that the Equality of Axioms and Theorems conjoined with the conception of Reason as Sagacity and Illation implies that there 
are reasons for axioms, and, therefore, axioms are not axioms at all. It is this point that is summarized in his sarcastic question,

$[\mathrm{H}]$ ow can it with any tolerable Sence be suppos'd, that what was imprinted by Nature, as the Foundation and Guide of our Reason, should need the Use of Reason to discover it? (Essay I.ii.10).

Since Locke takes his view of Reason as Sagacity and Illation to be given, he concludes that the Rational Accessibility Criterion of Innateness implies a contradiction. What I've argued is that the way to avoid this argument, and thus defend the Rational Accessibility Criterion of Innateness, is to assert that mental content can be fixed adverbially. That claim defeats Locke's inference from the conjunction of the claim of Equality of Axioms and Theorems and the view of Reason as Sagacity and Illation, to the conclusion that axioms are not axioms; axioms could be in the mind in the exercise of reason even though reasons are not given for them. The Lockean reply to this objection is to deny that mental content can be fixed adverbially. But to ascribe such a denial to Locke is to weaken Yolton's interpretation.

Before considering objections to this argument it is important to headoff one possible source of misunderstanding. Note that in Essay I.ii, Locke is explicitly engaged not with a criterion for the innateness of an idea, but with a criterion for the innateness of a proposition. He turns directly to the question of whether or not there are any innate ideas in Essay I.iv. Isn't it inaccurate, then, to describe Locke as arguing against the Rational Accessibility Criterion of Innateness, which is a criterion for innate ideas, rather than innate propositions? No, for Locke thinks that if a proposition is innate, then the ideas out of which the proposition is built are innate. As he puts the point:

[I]t may, with as much probability, be said, That a Man hath $100 l$. sterling in his Pocket, and yet denied, that he hath there either Penny, Shilling, Crown, or any other Coin, out of which the Sum is to be made up; as to think, that certain Propositions are innate, when the Ideas about which they are, can by no means be supposed to be so (Essay I.iv.19).

Someone, then, who holds the view to which Locke is explicitly objecting in Essay I.ii is committed, he thinks, to the claim that the ideas that make up the axioms are innate for the reason described in the Rational Accessibility Criterion. If it is possible, then, to bring content into the mind through the manner in which one accepts a proposition, then it is possible to bring ideas into the mind through the manner in which one perceives those ideas. This is precisely what Locke's anti-nativist argument commits him to denying; but it is also just what Yolton's Locke must insist upon in order to account for discrepancies between appearance and reality. 
The argument just offered can be resisted. It might be suggested, for instance, that there's a disanalogy between the mental activities involved in, on the one hand, grasping a proposition through reason and, on the other, sensory perception. We might then suggest that Locke could allow the adverbial supplementation of mental content in the case of sense perception while denying it in the case of the activity of giving and grasping reasons for particular propositions. What really motivates this line of objection is the thought that sensorily perceiving an object in a particular manner is quite different from presupposing the indubitability of certain propositions (logical axioms) when engaging in a certain mental activity (namely the activity of giving reasons). In the latter case, what is meant is that the activity of giving reasons would have no point or purpose if the axioms of logic were not accepted by the person engaging in the activity; without such a presupposition, no intermediate ideas could serve to support a claim of an agreement between the ideas they mediate between. But in what sense could the point or purpose of perceiving an apple depend on a supposition of its redness? The worry is that there appears to be no analogy between perceiving-in-a-manner, and presupposing logical axioms.

In response to this objection, note that one need not have a very clear idea of the notion of supplementing mental content adverbially (as I must confess I do not) in order to agree that if we allow adverbially determined content then any particular bit of content that a mental act has, could, in principle, derive from the manner in which that act is performed. This, by itself, is enough to admit that it is possible that the claim that the axioms are presupposed in exercises of reason is to be accounted for by saying that the relevant mental act is performed in a manner that accounts for the fact that the content of the axioms is in the mind of the person engaging in that mental act. No one who accepts the coherence of the idea of adverbial content supplementation should deny this possibility, and Locke's anti-nativist argument rehearsed above does require denying it. So, although one could consistently maintain that sensory content is, in fact, supplemented adverbially and the content of axioms presupposed in the exercise of reason is not, in fact, included adverbially, one cannot consistently hold that sensory content is supplemented adverbially and deny the possibility that the content of axioms is included in exercises of reason because of the manner in which those mental acts are performed. There's a degree of analogy between sensory perception and exercises of reason that cannot be denied and would be sufficient to make trouble for Locke's anti-nativist argument were he to accept that any mental content, in any context, is fixed adverbially.

Another line of objection might suggest that Locke would not be bothered by the idea that the content of axioms could be included in the mind through the manner of awareness involved in the exercise of reason. After all, it is a further step from this claim to the claim that the content of 
thoughts about axioms are innate, and it is that conclusion that would bother Locke. It might be suggested, that is, that the very manner of awareness involved in the exercise of reason is acquired through experience, in which case Locke could maintain his anti-nativist conclusion while also holding that mental content is fixed adverbially. By similar reasoning, after all, Locke would not have to be a nativist about the idea of red in order to hold that the content of that idea is fixed adverbially. But this objection misses the mark. Locke is not trying to show, at this point, that mathematical concepts and the axioms that follow from them are not innate. He tries to show that in book II of the Essay by offering accounts of the way in which mathematical concepts are acquired through experience. What Locke is after here is a criterion for innateness under which the claim that ideas are innate is neither trivial - everything or nothing turns out to be innate - nor false. The criterion under consideration is the Rational Accessibility Criterion. What he is offering is an argument against the cogency of that criterion, not an argument for or against the native status of any particular set of concepts. To admit that content can be fixed adverbially is also to admit that the Rational Accessibility Criterion provides neither a trivial nor a false nativist view, and it is precisely that that Locke hopes to reject.

Perhaps the most powerful objection to my argument runs thus: ${ }^{7}$ Someone who believes that mental content can be supplemented adverbially and also holds that the content of logical axioms is in the mind because of the manner in which certain mental acts (the exercises of reason) are performed needn't see himself as developing the Rational Accessibility Criterion of Innateness. Such a person might say, instead, that there are really two different ways in which a proposition can be innate: either because it is discovered through the exercise of reason, or because it is presupposed by any exercise of reason. Perhaps the argument of Locke's rehearsed above is not intended to respond to someone who takes the second of these two disjuncts to be sufficient for innateness, but that still Locke allows that the content of the axioms could be in the mind in this way. If so, we would expect Locke to engage with (and reject) this further sufficient condition for innateness elsewhere. Arguably, he does so when in Essay I.ii.17-24 he addresses the view that a proposition is innate if self-evident to those who understand it. Therefore, the fact that Locke's argument against the Rational Accessibility Criterion of Innateness can be defeated by extending the list of those things known through reason to include those propositions that are included in our thoughts by virtue of the manner in which we think when using reason does not show that he rejects the possibility of an adverbial source of mental content. He might simply be leaving that possibility for discussion later. ${ }^{8}$

This objection is damaging to my argument only if Locke thinks that the class of propositions presupposed by an exercise of reason, on the one 
hand, and the class of those that are self-evident to someone who understands them, on the other, are the same class. Without this claim, there is no reason to think the discussion of Essay I.ii.17-24 to be aimed at those who think that the content of the axioms is in the mind innately because of the manner in which exercises of reason are performed. But, in fact, there is strong evidence to the contrary, for in rejecting the claim that a proposition is innate if self-evident to those who understand it, Locke claims that according to this criterion true propositions such as "Yellowness is not sweetness" (Essay I.ii.18) are innate, and he remarks,

But since no Proposition can be innate, unless the Ideas, about which it is, be innate, This will be, to suppose all our Ideas of Colours, Sounds, Tastes, Figures, etc. innate; than which there cannot be any thing more opposite to Reason and Experience (I.ii.18).

The argument that Locke offers here fails to discriminate between those propositions that are self-evident because they are presupposed by our exercises of reason, and those that are self-evident because the ideas involved manifestly agree or fail to agree. Further it only succeeds in rebutting the self-evidence criterion of innateness if all self-evident propositions are of the latter sort. So, someone trying to use an appeal to an adverbial source of content to establish the innateness of the logical axioms could object here. Such a person would say that what Locke has illustrated is the undeniable fact that the class of propositions presupposed by our exercises of reason is a proper subset of the class of selfevident propositions, a fact that is not troubling to someone who takes only the former class to be innate. Were Locke willing to admit that content could be supplemented adverbially, however, he would have to agree that his argument here unfairly equates two different criteria of innateness. We are then forced to hold either that Locke does not think that mental content can be supplemented adverbially, or else that his arguments against innate ideas fail for reasons that he himself accepts. Charity, it seems to me, demands the former interpretation.

Let's take stock. We've considered two possible supplemental sources of perceptual content consistent with the position Yolton attributes to Locke: relational qualities in the world, and ways of perceiving qualities of the world. I've argued that the first source only makes sense of cases of divergence between appearance and reality if the second source is also appealed to. Then I've argued that the second source can only be accepted by someone who eschews Locke's anti-nativist argument. Given that Locke, at least, accepts this argument, he must eschew the adverbial view of perceptual content. The conclusion that I want, however, is that all of this shows that Locke accepts the model of perception attributed to him by Reid and not the view attributed to him by Yolton. But this conclusion only follows if there isn't some third source of perceptual content 
that could be accepted by Yolton's Locke and which would allow for discrepancy between appearance and reality. In the next section, I want to draw out a third source of perceptual content that Locke himself, I will argue, recognizes. However, I'll also argue that that third source of perceptual content does not provide room for appearance-reality divergence.

\section{Another source of perceptual content}

In various passages in the late chapters of book II of the Essay, Locke specifies ways in which ideas are to be classified - as adequate or inadequate, real or fantastical, and true or false - through the ways in which they do and do not live up to that for which they were "intended". This intention-talk is rather puzzling. Rarely do we concoct ideas with an explicit intention, anyway, of doing anything with them. There are, of course, exceptions: I think of a soccer ball in order to test the powers of the man claiming to be able to read minds, for instance. But Locke seems to think that the distinctions between, for instance, adequate and inadequate ideas divide logical space: every idea is either adequate or inadequate, and thus he must think that every idea is intended for something. Although in places Locke seems to say that the relevant intentions are those of the person whose ideas are under consideration, this is probably not his settled view. Rather, Locke must mean that various ideas have a particular purpose, function or role. Ideas are to be classified as, say, adequate or inadequate in so far as they live up, or fail to live up, to that role in some way or another.

Locke's distinction between ideas of modes and ideas of substance tracks a distinction between two different purposes for which ideas are "intended". For instance, having argued that our ideas of modes are all of them adequate, Locke writes:

But in our Ideas of Substances, it is otherwise. For there desiring to copy Things, as they really do exist ... we perceive our Ideas attain not that Perfection we intend: We find they still want something, we should be glad were in them; and so are all inadequate. But mixed Modes and Relations, being Archetypes without Patterns, and so having nothing to represent but themselves, cannot but be adequate, every thing being so to it self. He that at first put together the Idea of Danger perceived, absence of disorder from Fear, sedate consideration of what was justly to be done, and executing of that without disturbance, or being deterred by the danger of it, had certainly in his Mind that complex Idea made up of that Combination: and intending it to be nothing else, but what it is; nor to have in it any other simple Ideas, but what it hath, it could not also but be an adequate Idea (Essay II.xxxi.3).

There are a couple of things to note about this passage. First, notice Locke's way of describing mode-ideas at the end of the passage: they are 
not intended to have in them any simple ideas but those that they do have in them. Taken literally, this suggests that in a substance-idea, by contrast, we intend that the idea have in it something more than what it has in it. Let's say that what an idea "has in it" is its presented content: it has in it all and only those aspects of the way things appear that are determined by the instrinsic features of the idea itself. By its very nature the intention involved in ideas of substance cannot be determined by the presented content of the idea. After all, the intention, as Locke describes it, is that the idea should represent more than what it presents. The intention determines whether the idea is a mode-idea or a substance-idea. So, assuming one has a different thought depending on which category one's idea falls into, and assuming that what makes two thoughts different is that they have different content, the passage seems to commit Locke to the view that something beyond the presented content of one's idea (namely, the idea's function or purpose) sometimes contributes to the full content of one's thought.

The passage also describes the two different functions of ideas of substance and mode. If the idea's purpose is to represent actual things, then it is an idea of substance; if it's purpose is to serve as a tool for the sorting and systematizing of the particulars one encounters, then it is an idea of a mode. This difference in function makes a difference to the content of thoughts involving these different ideas, as follows: Since an idea of substance is intended to represent features of an object beyond those that it explicitly presents to the mind, it succeeds in being about parts of the world that the intrinsically identical mode-idea does not concern. To have an idea of substance is, seemingly paradoxically, to think about those features of an object which your idea does not present to you.

To illustrate, imagine that before me I have an object that is round, red, and rough. I am not touching the object, and have in my mind a complex idea that presents to me only roundness and redness. Further, imagine that I know nothing of features of the object other than its roundness and redness. Were I asked if the object is rough, I would have no opinion either way. Now imagine this idea is a mode-idea, intended to do no more than to help me to classify the particulars around me. Then my idea is in no sense about the object's roughness. All that would happen were roughness added to the presented content of my idea is that I would have a new tool for classifying particulars, and systematizing my experience. I would not have a better tool than I have when I have the idea that includes nothing but round and red, but instead, just a new conceptual category: round-red-rough. As Locke would put it, my idea would be no more "adequate" were it's presented content expanded to include roughness. Now imagine that the idea is a substance-idea, intended to represent this particular thing as it is, quite independently of my thought. Then my idea is about all of the object's features, although some, in particular the 
object's roughness, are not presented to me by the idea. My idea manages to be about a feature of the object that is not exhibited to my mind. The idea manages to do this solely because it is intended to stand for the object, including the features of the object about which I know nothing. My mental model would improve - my idea would become more adequate - were my idea to include the idea of roughness, but not because it came now to be about a feature that it was not previously about, but, instead, because it would then represent as it is a feature that my idea was previously about only as an I-know-not-what. Substance-ideas are about what they do not explicitly represent because they are about whatever features the object has, even those that the idea does not explicitly represent the object as possessing.

Recall that what makes it possible to account for (or, at least, leave room for) divergence between appearance and reality within a direct realist view of the sort that Yolton attributes to Locke is a claim to the effect that those things that determine how the world is are distinct from those that determine how things appear. We considered two possible sources for perceptual content that satisfy this demand: properties of the mental act of awareness (that is, ways of perceiving) and relational properties of objects (that is, being such as to appear a certain way). Neither source by itself, it's been argued, can be accepted by Locke. But now we have a third possible candidate that Locke himself seems to be proposing: the content of a thought is determined, in part at least, by the purpose or function that the perceived idea is meant to serve. Since this function is not what accounts for the features of the object perceived, it is theoretically possible that appeal to it could leave room for appearance-reality divergence.

But does it? Unfortunately for the direct realist interpretation of Locke, it does not. The problem is that the only additional content that the idea's function supplies is of "something more" than what is to be found explicitly in the idea. There is a class of cases of appearance-reality divergence that can be accounted for here, but the class is very small. For instance, my idea of the monster on the movie screen is an idea of substance I represent the object as possessing features other than those explicitly presented to me in my idea - but, in fact, the object possesses no features beyond those of which I am explicitly aware. There is no fact of the matter, for instance, about whether or not the underbelly of the beast is covered with polka dots if that matter isn't settled by anything that appears on the screen. So, in this case, since my idea is an idea of substance, and since the monster has no qualities beyond those explicitly presented, how things appear to me, and how they are, diverge. But most cases are not like this. Usually, there is divergence between appearance and reality precisely because features are presented to one which are not to be found anywhere in reality. How could the function of an idea supply, say, the 
pinkness of the white cat perceived in pink light? How could it supply the size differential of the two ten foot trees one of which is farther away than the other? Although an idea's function can supply content to a thought that is not presented, that function cannot supply the kind of content to perceptual experience that an act-based view of the mental needs in order to account for most cases of divergence between appearance and reality.

\section{Conclusion}

Under the view of perception that I, following Reid, attribute to Locke, much of the content of perceptual experience is given by the features of the directly perceived item, the idea. This is to say that at least some features of the world can be encountered directly and unproblematically: namely, the features of our ideas. It is no surprise that Reid should have seen this concession as an invitation to direct realism. As Reid puts the point himself:

We are at a loss to know how we perceive distant objects; how we remember things past; how we imagine things that have no existence. Ideas in the mind seem to account for all these operations. They are all by the means of ideas reduced to one operation; to a kind of feeling, or immediate perception of things present and in contact with the percipient ... But this feeling, or immediate perception, is as difficult to be comprehended, as the things which we pretend to explain by it (Reid, 2002, p. 185).

If the encounter with the idea, the encounter that gives rise to contentful mental experience, is so unproblematic, why is it thought necessary at all? Why not allow that we have the very same encounter with objects external to our minds?

Little can be said in response to this except to appeal to the theoretical advantages of the model of the mental that Locke, I've argued, espouses. Perhaps some things are explained under that model that cannot be explained under the act-based view espoused by Reid himself, and attributed to Locke by Yolton. One problematic case for the Reidian model are cases of discrepancy between appearance and reality. What has been argued here is that the ways that a Reidian might respond to such difficulties are not available to Locke: they open doors to substantive philosophical positions friendly to nativism that Locke took himself to have closed. And so it is best to read Locke as endorsing a veil of perception, just as he was thought to have done by many of his eighteenth-century interpreters. ${ }^{9}$

School of Philosophy

University of Southern California 


\section{NOTES}

${ }^{1}$ Not all of Locke's early intepreters read him in this way. For discussion of some who interpreted him otherwise, see Yolton, 1984, pp. 98-101. I do not entirely endorse Yolton's interpretation of Reid, however. Yolton correctly points out that Reid thinks Locke uses the term 'idea' sometimes to mean a mental object, sometimes a mental act. However, Yolton doesn't point out that Reid also thinks that Locke's official position does not leave open the construal of ideas as mental acts whose objects are extra-mental particulars. When Locke uses the term 'idea' to refer to a mental act, he is slipping on his official position, according to Reid.

${ }^{2}$ Lex Newman has suggested to me in conversation that things might be more complicated than I suggest here. If Locke held that there is a mere "distinction of reason" between the modification of the mind, the mental act, and its intentional content, then there could be a sense in which there is a tertium quid in his theory of perception (when ideas are conceived of as intentional contents) and a sense in which there is none (when ideas are conceived of as mental acts). I am not certain, however, how different this interpretation is from the view that Yolton attributes to Locke. On both views, when external obects are perceived they are the immediate obects of a mental act that attaches to the object by virtue of the act's intentional content. But the intentional content is not, itself, an object of perception.

${ }^{3}$ Yolton, 1984, pp. 88-94. To give just one of Yolton's examples, Locke writes, "To ask, at what time a Man has first any Ideas, is to ask, when he begins to perceive; having Ideas, and Perception being the same thing." (Essay II.1.9).

${ }^{4}$ There is a logical space for a representational realist of the sort Reid takes Locke to be to claim that features of ideas fix perceptual content only when there is divergence between appearance and reality. This, however, would be to deny that there is a "common factor" in veridical perception, on the one hand, and sensory illusion, on the other.

${ }^{5}$ There might be other possibilities. The final section of this paper discusses one possible third source of perceptual content. However, if there are other possibilities yet - other explanations for how appearance and reality can diverge on the view that Yolton attributes to Locke - then there is room for an objector to insist that Locke does hold the view Yolton attributes to him and accepts this alternative explanation. Although I think it unlikely that such an objection can be constructed (because I think it unlikely that yet another explanation can be found that Locke would be willing to accept with all its implications) nothing to be said here rules out the possibility.

${ }^{6}$ Strictly speaking the relation between the mediating ideas and those they mediate between will not always be "agreement". When the relevant ideas do agree, we have genuine knowledge; when we merely suppose them to agree, we have belief, or "probability".

${ }^{7}$ This objection was raised by Jonathan Vogel at the 2000 Pacific APA where an earlier version of this paper was presented. Martha Bolton developed it in further discussion and convinced me that my response to Vogel at the time was not satisfactory.

${ }^{8}$ This objection can be supported further by noting that in Essay I.II.10, immediately following his attack on the Rational Accessibility Criterion of Innateness, Locke mentions the view that a proposition is innate if self-evident to those who understand it and says that he will be discussing that possibility soon.

${ }^{9}$ Thanks to Martha Bolton, Vere Chappell, Peter Graham, Robin Jeshion, Lex Newman, John Rogers and Jonathan Vogel, all of whom offered valuable comments on an earlier draft of this paper. 